\title{
Public Awareness toward Cervical Cancer among Saudi Females in AL- Ahsa city, Saudi Arabia
}

\author{
Mahdi Mousa Al-Muhanna, Sadiq Jawad Alkhalifah, Mufeed Mohammed Al-Muhanna, Jawad \\ ahmad alkhars, Afnan Tawfiq Hanfish, Zainab moosa Al-yousif, Sukaina Hussain ALIbrahim, \\ Sakinah Salman ALHumud, Rabab abdrab alnabi AlMajed, Fatimah basim bin alshaykh, \\ Khadijah Jassim AlHassan \\ Maternity and children hospital in Al-Ahsa city, Saudi Arabia
}

\begin{abstract}
Background: Cervical cancer is the third most common malignancy in women worldwide, and it leads to death if not diagnosed early and treated properly. Also, it is considered as one of the most common cancer related death in developing countries.

Objectives: To assess the level of awareness toward cervical cancer, risk factors, early detection and prevention among Saudi females.

Methods: a cross-sectional study was carried out among 450 Saudi females aged 18-60 years old in the period from August 2018 to September 2018. The participants were randomly chosen for this study.

Results: 450 participated Saudi females have filled the questionnaires. The vast majority of participants had heard about cervical cancer $(86.7 \%)$ but most of participants $(80 \%)$ do not know if HPV infection could transmit from husband to wife. More than half of participants (61\%) knew that there is available vaccine against human papilloma virus. $90 \%$ of participants have never done cervical screening to detect HPV or cervical cancer.

Conclusion: There is low level of awareness towards cervical cancer and its prevention's methods among Saudi females. Thus, we need to increase the educational campaigns to increase the level of awareness about this fetal disease and its prevention methods.
\end{abstract}

Keywords: Cervical cancer, Female, Saudi Arabia, Awareness.

\section{INTRODUCTION}

Cervical cancer is the third most common malignancy in women worldwide, and it leads to death if not diagnosed early and treated properly. Also, it considered as one of the most common cancer related death in developing countries. ${ }^{(1)}$.

More than half million new cases are diagnosed each year around the world with cervical cancer and about (80\%) of cervical cancer cases occur in low socioeconomic countries where it is the most common type of cancer $^{(2)}$. In Saudi Arabia Cervical cancer is the 12th most common cancer among women (3). Human Papilloma Virus (HPV) infection known as risk factor for cervical cancer, thus prevention of HPV infection will lead to decrease the incidence of cervical cancer. In addition, there is available vaccine against HPV and should be used for both males and females ${ }^{(4)}$.

\section{METHODS}

- A cross-sectional study was distributed among 450 Saudi females aged 18-60 years old in the period between August 2018 and
September 2018. The participants were randomly chosen for this study.

- A structured questionnaire was designed to assess the awareness of cervical cancer, early detection, and prevention of risk factors.

- $\quad$ SPSS version 21was used for data entering and analysis.

- Ethical and privacy purposes were ensured for every participants and this study was done by residents from the maternal hospital in Al-Ahsa city.

\section{RESULTS}

Four hundred and fifty participants were included in this study; all of the participants were female $(100 \%)$ and more than half of respondents aged 3140 years old $(51.5 \%)$. Regarding the education level, the vast majorities of participants $(71 \%)$ were still in college or had college degree. (table1) 
Table 1: Demographic information of participants (450)

\begin{tabular}{|l|l|l|l|}
\hline \multicolumn{2}{|l|}{ Questions } & NO & $\%$ \\
\hline \multirow{2}{*}{ 1- Gender } & Female & 450 & 100 \\
\cline { 2 - 4 } & Male & 0 & 0 \\
\hline $\begin{array}{l}\text { 2- Education } \\
\text { level }\end{array}$ & $\begin{array}{l}\text { College and } \\
\text { above }\end{array}$ & 320 & 71.1 \\
\cline { 2 - 4 } & school & 130 & 28.9 \\
\hline \multirow{3}{*}{$3-$ age } & $20-30$ & 112 & 24.9 \\
\cline { 2 - 4 } & $31-40$ & 232 & 51.5 \\
\cline { 2 - 4 } & $41-60$ & 106 & 23.6 \\
\hline
\end{tabular}

Table 2 shows the questions related to the level of awareness and knowledge toward cervical cancer among participants (450); the vast majority of respondents had heard about cervical cancer $(86.7 \%)$ but most of participants have never heard about human papilloma virus $(66.2 \%)$. Half of participants believed that cervical cancer is a preventable disease. More than half of participants (61\%) knew that there is available vaccine against human papilloma virus but (59.3\%) do not know if this vaccine to be used by both males and females. Unfortunately, most of participants $(80 \%)$ do not know if this infection could be transmitted from husband to wife. More than half of participants believed that regular HPV screening will protect against cervical cancer $(57.3 \%)$ but only $(9.8 \%)$ of all participants have done the screening.

Table 2: Regarding the 8 questions for general knowledge

\begin{tabular}{|l|l|l|l|l|}
\hline Questions & \multicolumn{2}{|c|}{ Ye } & \multicolumn{2}{c|}{ No } \\
\cline { 2 - 5 } & Count & Count & \% \\
\hline 1- Have you ever heard about cervical cancer? & 390 & $86.7 \%$ & 60 & $13.3 \%$ \\
\hline 2- Do you know that cervical cancer is a preventable disease? & 226 & $50.2 \%$ & 224 & $49.8 \%$ \\
\hline 3- Have you ever heard about human papilloma virus? & 152 & $33.8 \%$ & 298 & $66.2 \%$ \\
\hline $\begin{array}{l}\text { 4- Have you heard about a vaccine that can prevent cervical } \\
\text { cancer? }\end{array}$ & 275 & $61.1 \%$ & 175 & $38.9 \%$ \\
\hline $\begin{array}{l}\text { 5- Do you know that this vaccine is available for both males and } \\
\text { females? }\end{array}$ & 183 & $40.7 \%$ & 267 & $59.3 \%$ \\
\hline $\begin{array}{l}\text { 6- Do you know that infected male can transmit HPV to his wife? } \\
\text { 7- Do you believe that regular HPV screening will protect } \\
\text { against cervical cancer? }\end{array}$ & 258 & $57.3 \%$ & 192 & $42.7 \%$ \\
\hline \begin{tabular}{l} 
8- Have you ever done screening to detect cervical cancer? \\
\hline
\end{tabular} & 44 & $9.8 \%$ & 406 & $90.2 \%$ \\
\hline
\end{tabular}

\section{DISCUSSION}

Most of cervical cancer cases is caused by human papilloma virus and may it is difficult to detect the infection early without screening. The diagnostic tool to detect this infection is Pap smear and are reported as either a low-grade squamous intraepithelial lesion (LGSIL) or a highgrade squamous intraepithelial lesion (HGSIL).

In Saudi Arabia there are many careless females whom never thought to obtain annual Pap smear testing and who have an HGSIL may progressed to invasive cancer of the cervix. The symptoms of cervical cancer are vaginal bleeding between periods or after sexual intercourse, dyspareunia, and fullness in the pelvis ${ }^{(5)}$. The HPV vaccine protects against Human Papillomavirus (HPV).
Research showed that when boys and girls are vaccinated early - at 11 or 12 - they're better protected HPV, including certain cancers and genital warts ${ }^{(4)}$.

The same number was found by a study done in Mecca city - Saudi Arabia. They found that only $20.1 \%$ of the population has heard about the vaccine ${ }^{(6)}$. A higher level of awareness was reported in a study conducted in Hungary; they reported that about one-third of the population have heard about the vaccine. ${ }^{\left({ }^{6}\right)}$ There are several other studies to examine the role of HPV DNA testing as a primary screening method for cervical cancer are underway. In addition, an effective therapeutic and preventive vaccines may contribute significantly to control and 
prevention of cervical cancer.

\section{CONCLUSION}

The final results showed that there is defect in the majority of the participants' knowledge and practice regarding Human Papilloma Virus prevention measures, transmission and its relation to cause cervical cancer. Thus, there is a great need to increase the educational campaigns in the public places to improve the level of awareness about this fatal disease.

\section{REFERENCES}

1. Ferlay J, Shin HR, Bray F, Forman D, Mathers C, Parkin DM(2010): Cancer Incidence and Mortality Worldwide: IARC CancerBase No. 10 [Internet]. Lyon: International Agency for Research on Cancer. Int J Cancer, 127(12):2893-917.

2. Young $t(2009)$ : current status of cervical cancer and HPV infection in Korea, doi:10.3802/jgo.

3.Cancer incidence report in Saudi $\operatorname{Arabia}(2007)$ :

https://nhic.gov.sa/eServices/Documents Incidence\%20Report\% 202007.pdf

4. Michels K (2009):HPV vaccine for all. The Lancet., 374 (9686): 268 - 270.

5. Black L, Zime, G, Short M et al.(2009): Literature review of human papillomavirus vaccine acceptability among women over 26 years. Vaccine, 27: 1668-1673.

6. Abdulrahim G (2012): scholar.google.com/citations?user=fil euq EAAAAJ \& $\mathrm{hl}=\mathrm{en}$. 